\title{
Regioselectivity in the $[2+2]$ cyclo-addition reaction of triplet carbonyl compounds to substituted alkenes (Paterno-Büchi reaction): A spin-polarized conceptual DFT approach
}

\author{
B PINTÉR, ${ }^{1}$ F DE PROFT, ${ }^{2}$ T VESZPRÉMI ${ }^{1}$ and P GEERLINGS ${ }^{2} *$ \\ ${ }^{1}$ Inorganic Chemistry Department, Budapest University of Technology and Economics (BUTE), Szent \\ Gellért tér 4, H-1521, Budapest, Hungary \\ ${ }^{2}$ Eenheid Algemene Chemie (ALGC), Vrije Universiteit Brussel (VUB), Faculteit, Wetenschappen, \\ Pleinlaan 2, 1050 Brussels, Belgium \\ e-mail: pgeerling@vub.ac.be
}

\begin{abstract}
Regioselectivity of the photochemical [2+2] cyclo-addition of triplet carbonyl compounds with a series of ground state electron-rich and electron-poor alkenes, the Paterno-Büchi reaction, is studied. Activation barriers for the first step of the triplet reaction are computed in the case of the O-attack. Next, the observed regioselectivity is explained using a series of DFT-based reactivity indices. In the first step, we use the local softness and the local HSAB principle within a softness matching approach, and explain the relative activation barriers of the addition step. In the final step, the regioselectivity is assessed within the framework of spin-polarized conceptual density functional theory, considering response functions of the system's external potential $v$, number of electrons $N$ and spin number $N_{s}$, being the difference between the number of $\alpha$ and $\beta$ electrons in the spin-polarized system. Although the concept of local spin philicity, introduced recently within this theory, appears less suited to predict the regioselectivity in this reaction, the correct regioselectivity emerges from considering an interaction between the largest values of the generalized Fukui functions $f_{\mathrm{ss}}$ on both interacting molecules.
\end{abstract}

Keywords. Regioselectivity; cyclo-addition of triplet carbonyl compounds; spin-polarized conceptual DFT approach.

\section{Introduction}

The Paterno-Büchi reaction ${ }^{1-4}$ (figure 1), i.e. the formation of oxetanes via photochemical cyclo-addition of aldehydes and ketones to alkenes, is the most general method for the synthesis of four-membered oxygen heterocyclic rings (oxetanes) in a regio- and stereoselective manner. An impressive number of papers, both preparative $^{5-8}$ and mechanistic, ${ }^{9-13}$ have been published in this field. Mechanistic studies have shown that the cyclo-addition generally proceeds through the attack of an $\left(n, \pi^{*}\right)$ excited carbonyl compound on a groundstate olefin. For oxetane formation to occur, the excited state energy of the olefin must be higher than that of the ketone so that energy transfer does not dominate the reaction. ${ }^{14-17}$ The reaction occurs for both the first singlet and triplet ${ }^{1,3}\left(n, \pi^{*}\right)$ excited state of the carbonyl compounds. ${ }^{3,4}$ The reaction is known to proceed via 1,4-diradicals which were detected experimentally in transient spectroscopy studies. ${ }^{18}$ The

*For correspondence
Paterno-Büchi cyclo-addition, proceeding through triplet manifold, exhibits good regio- and stereoselectivity and the most general adopted method to predict the major product is the most stable biradical rule, which was predicted first by Zimmerman. ${ }^{19}$ There are exceptions to this rule; special methods were suggested to predict the major product, for example attack on the less hindered side of the molecule, the relative stability of the adducts ${ }^{20}$ or kinetic control. ${ }^{21}$

Rationalization of the model of cyclo-addition to unsymmetrical substituted olefins ${ }^{20}$ has also led to postulating a nonconcerted mechanism (predominant isomer), and the results show that product ratios are not always simply predicted from the stability of the<smiles>[X]C=CC(C)C1([R])OCC([Y])C1([R])[R]</smiles>

Figure 1. [2+2] Photo-cyclo-addition of a triplet carbonyl compound to a singlet ethylene. 
intermediate radicals. The results suggest that the additions occur via one excited quenchable state, most likely the $\left(n, \pi^{*}\right)$ triplet state of the carbonyl compounds. Other regio- and stereoselective PaternoBüchi reactions involve the use of phenylglioxylates as the olefin components ${ }^{22}$ and numerous electronrich and electron-poor alkenes at the olefin side. The results clearly demonstrate that the electron density of the olefins affects the mechanism; the reaction for electron-rich alkenes is rapid, highly regio- and stereoselective, without competitive Norrish type II reactions. When less electron-rich alkenes are used, the Norrish type II reaction becomes competitive. One can predict the regioselectivity with the "biradical rule", the instant of the intersystem crossing determines the stereoselectivity of the products.

In contrast to unsymmetrically substituted allenes, in the case of 9-methyl-1,2-butadiene, lower regioselectivity, but higher stereoselectivity was found. ${ }^{23}$ In the reaction between styrene and benzaldehyde ${ }^{24}$ there is a $\pi-\pi$ overlap which has an impact on the distribution of products because there is cis-2,2-diphenyloxetane obtained from the irradiation. For silylated cinnamyl alcohol and benzaldehyde noncovalent tethering was reported (but not $\pi-\pi$ overlap) since there is only one stereoisomer obtained and no side reactions. If tethering is involved, then phenyl groups must be held in opposite directions in the coordinated structure due to steric effects. Recently, a couple of studies reported the hydrogen-bond interaction in the excited singlet and triplet states, ${ }^{25,26}$ influencing the ratio of regioand stereoisomers. Palmer et $a l^{9}$ performed a detailed MC-SCF/6-31G* study of the singlet and triplet Paterno-Büchi reaction using formaldehyde and ethylene as model systems, investigating both the formation of the oxetane via carbon-carbon and carbon-oxygen attacks. They found the $\mathrm{C}-\mathrm{O}$ attack to be non-concerted, the first step of the reaction involving, in the case of the triplet pathway, the direct formation of the diradical intermediate. One of their other conclusions stated that the triplet diradicals generated in this reaction have similar energies and geometries to the singlets. Nguyen et $a l^{11}$ used the Fukui functions, the local softness and the local hard and soft acids and bases principle for the regioselectivity of oxetane formation in the lowest ${ }^{3}\left(n, \pi^{*}\right)$ state of carbonyl compounds and their results are in good agreement with the experimental data. In their approach, they considered this reaction to be a concerted onestep cyclo-addition. In 2004, D'Auria et $a l^{20}$ reported that an approach based on the frontier orbitals control is more efficient in explaining the photochemical behavior for furan derivatives than the most stable biradical rule.

In this contribution, we carry out a high level theoretical study on the regioselectivity of the $\mathrm{Pa}$ terno-Büchi photocyclo-addition of triplet acetone and acetophenone on a series of substituted alkenes, involving both electron-poor and electron-rich alkenes. Next to the localization of the transition structures of the biradical formation step of this reaction, the regioselectivity is assessed within the framework of both non-spin polarized and spin-polarized conceptual density functional theory. ${ }^{27}$

\section{Theory and computational details}

Next to the well-established computational advantages, density functional theory (DFT) is the source for the introduction of a series of concepts and principles, readily used by chemists but often defined on an empirical basis. This aspect of DFT, in which chemical quantities are identified with response functions of the system's energy with respect to either the number of electrons $N$, the external (i.e. due to the nuclei) potential $\mathrm{V}(\mathbf{r})$ or both was termed "conceptual DFT" by R G Parr. The first-order derivative of the energy of the system with respect to the number of electrons is the chemical potential $\mu$, identified by Parr et $a l^{28,29}$ with the negative of the electronegativity $\chi$ :

$$
\mu=-\chi=(\partial E / \partial N)_{v} .
$$

The chemical hardness $\eta$ of the system ${ }^{30}$ was quantified by Parr and Pearson as: ${ }^{31}$

$$
\eta=\frac{1}{2}\left(\partial^{2} E / \partial N^{2}\right)_{v}
$$

which, in a finite difference approximation, can be written as:

$$
\eta \approx(I E-E A) / 2,
$$

where $I E$ and $E A$ are the vertical ionization energy and electron affinity of the systems respectively. The inverse of the global hardness is the global softness $S:^{32}$

$$
S=1 / \eta=(\partial N / \partial \mu)_{\vee} \approx 1 /(I E-E A) .
$$

The local counterpart of this quantity, the local softness $s(\mathbf{r})$, is introduced as: $:^{32,33}$ 


$$
s(\mathbf{r}) \equiv\left(\frac{\partial \rho(\mathbf{r})}{\partial \mu}\right)_{N}=\left(\frac{\partial \rho(\mathbf{r})}{\partial N}\right)_{N}\left(\frac{\partial N}{\partial \mu}\right)_{V}=S f(\mathbf{r}),
$$

where $f(\mathbf{r})$ is the Fukui function, a reactivity index introduced by Parr and Yang. ${ }^{34}$ Due to the discontinuity of the electron density with respect to the number of electrons, three different Fukui functions can be introduced, representing the case of a nucleophilic attack $\left(f^{+}\right)$, an electrophilic attack $\left(f^{-}\right)$or a neutral (radical) attack $\left(f^{0}\right)$ :

$$
\begin{aligned}
& f^{+} \equiv(\partial \rho(\mathbf{r}) / \partial N)_{\vee}^{+} \approx \rho_{N+1}(\mathbf{r})-\rho_{N}(\mathbf{r}), \\
& f^{-} \equiv(\partial \rho(\mathbf{r}) / \partial N)_{\vee}^{-} \approx \rho_{N}(\mathbf{r})-\rho_{N-1}(\mathbf{r}), \\
& f^{0} \equiv\left(f^{+}+f^{-}\right) / 2 \approx 1 / 2\left(\rho_{N+1}(\mathbf{r})-\rho_{N-1}(\mathbf{r}),\right.
\end{aligned}
$$

where $\rho_{N+1}(\mathbf{r}), \rho_{N}(\mathbf{r})$ and $\rho_{N-1}(\mathbf{r})$ are the electron densities of the $N+1, N$ and $N-1$ electron system respectively, all obtained at the geometry of the $\mathrm{N}$ electron system, due to the fact that the derivative is taken at a constant external potential. These Fukui functions can be condensed to the nuclei by using an atomic charge partitioning scheme, $N_{k}(N+1), N_{k}(N)$ and $N_{k}(N-1)$ representing the electron populations on atom $k$ in the $N+1, N$ and $N-1$ electron system: ${ }^{35}$

$$
\begin{aligned}
& f_{k}^{+} \approx N_{k}(N+1)-N_{k}(N), \\
& f_{k}^{-} \approx N_{k}(N)-N_{k}(N-1), \\
& f_{k}^{0} \approx \frac{1}{2}\left(N_{k}(N+1)-N_{k}(N-1) .\right.
\end{aligned}
$$

The condensed local softness is the product of the global softness $S$ with $f_{k}^{i}$ at a given site $k$ :

$$
\mathrm{s}_{k}^{i}=S \cdot f_{k}^{i}
$$

where $i$ equals either,+- or 0 depending on whether the system undergoes a nucleophilic, electrophilic or radical attack. A theoretical justification of the HSAB-principle was provided by Chattaraj, Lee and Parr. ${ }^{36}$ This principle has been applied many times in recent years, both at the local and the global level, for the rationalisation of regioselectivity and reactivity of many problems. ${ }^{37}$

The above mentioned response functions can be used to describe changes from one ground state to another. The Hohenberg-Kohn theorems, ${ }^{38}$ on which density functional theory is based, were also initially developed for the ground states but could later on be generalized to time-dependent electron densities and external potentials. ${ }^{39,40}$ Applications of these DFT based reactivity indices to excited states have moreover been scarce. $^{41}$

In the present application, one of the reaction partners, i.e. the carbonyl compound, is in its excited triplet state for which the electron densities of the $\alpha$ and $\beta$ electrons are different, corresponding to a spinpolarized chemical system. We are thus working within the framework of spin-polarized DFT. ${ }^{42}$ Galván, Vela and Gázquez have introduced spin-polarized conceptual DFT, deriving expressions for, among others, the spin potential $\mu$ s, the spin hardness $\eta_{s s}$ and the Fukui functions $f_{s s}{ }^{43 a}$ (For a detailed account of other reactivity indices introduced within this framework, see ref. 43).

The spin potential $\mu_{s}$ is introduced as the partial derivative of the energy with respect to the spin number, $N_{s}\left(=N_{\alpha}-N_{\beta}\right)$, since it provides a measure for the tendency of the system to change its spin polarization:

$$
\mu_{s}=\left(\partial E / \partial N_{s}\right)_{N, \forall(\mathbf{r}) \cdot \mathbf{B}}
$$

where $\mathbf{B}$ is the external magnetic field.

The second-order partial derivative of the energy with respect to $N_{s}$ is the spin hardness $\eta_{s s}$ :

$$
\eta_{S S}=\left(\partial \mu_{s} / \partial N_{s}\right)_{N, v(\mathbf{r}) \cdot \mathbf{B}}=\left(\partial^{2} E / \partial N_{s}^{2}\right)_{N, v(\mathbf{r}) \cdot \mathbf{B}} .
$$

The change of the spin density $\rho_{s}(\mathbf{r})$ upon change in spin number $N_{s}$ is governed by the Fukui function $f_{S S}:$

$$
f_{S S}=\left(\partial \rho_{s}(\mathbf{r}) / \partial N_{s}\right)_{N, \forall(\mathbf{r}), \mathbf{B}}
$$

The total energy of a system can be expanded in a Taylor series around the reference ground state and the energy difference between the ground and promoted state, at constant total number of electrons and external potential, can be written up to second order as:

$$
\Delta E_{\mathrm{v}, N} \approx \mu_{s}^{0}+\frac{1}{2} \eta_{s s}^{0}\left(\Delta N_{s}\right)^{2} .
$$

In this expression, $\mu_{s}^{0}$ must always be calculated in a given direction, substituting $\mu_{s}^{0}$ by $\mu_{s}^{+}$when describing changes with increasing spin number, and by $\mu_{s}^{-}$ when the spin number is decreasing. The chemical potentials $\mu_{s}^{+}$and $\mu_{s}^{-}$can be approximated as: 


$$
\mu_{s}^{+} \approx\left(\varepsilon_{\text {LUMO }}^{\alpha}-\varepsilon_{\text {HOMO }}^{\beta}\right) / 2
$$

and

$$
\mu_{s}^{-} \approx\left(\varepsilon_{\mathrm{HOMO}}^{\alpha}-\varepsilon_{\mathrm{LUMO}}^{\beta}\right) / 2,
$$

where $\varepsilon_{\mathrm{HOMO}}^{\alpha}, \varepsilon_{\mathrm{HOMO}}^{\beta}, \varepsilon_{\mathrm{LUMO}}^{\alpha}$ and $\varepsilon_{\mathrm{LUMO}}^{\beta}$ are the orbital energies of the $\alpha$ and $\beta$ HOMO and LUMO orbitals respectively. The spin hardness can be evaluated as:

$$
\eta_{S S}^{0} \approx\left[\mu_{s}^{-}\left(M^{\prime}\right)-\mu_{s}^{+}(M)\right] / 2,
$$

where $\mu_{s}^{-}\left(M^{\prime}\right)$ is the spin potential of the higher multiplicity $\left(M^{\prime}\right)$, towards a decrease in the spin number and $\mu_{s}^{+}\left(M^{\prime}\right)$ the spin potential of the lower multiplicity $(M)$ towards an increase in $N_{s}$. It measures the curvature of the $E$ versus $N_{S}$ curve in the given interval. Within this framework, Pérez et $a l^{44}$ defined the concepts spin-philicity and spin-donicity. The spinphilicity index $\omega_{s}^{+}$of the system can be defined as: ${ }^{44}$

$$
\omega_{s}^{+} \equiv\left(\mu_{s}^{+}\right)^{2} / 2 \eta_{s s} .
$$

In the direction of a decreasing spin number, the spin-donicity index is given as:

$$
\omega_{s}^{-} \equiv\left(\mu_{s}^{-}\right)^{2} / 2 \eta_{s s} .
$$

Both indices are shown to be interesting quantities in the discussion of spin catalysis phenomena and can be invoked to explain singlet-triplet gaps. ${ }^{41 \mathrm{f}, 41 \mathrm{~g}}$ De Proft et $a l^{45}$ introduced the concepts of local spin-philicity and donicity for use in regioselectivity studies. The spin-philicity can be calculated condensed on a atom $k$ in the molecule, as:

$$
\omega_{s, k}^{+}=\left[\left(\mu_{s}^{+}\right)^{2} / 2 \eta_{s s}\right] f_{s s, k}^{+},
$$

where $f_{s s}^{+}$denotes the spin Fukui function in the direction of increasing spin number. Similarly we define the local spin-donicity, condensed on an atom $k$, as:

$$
\omega_{s, k}^{-}=\left[\left(\mu_{s}^{-}\right)^{2} / 2 \eta_{s s}\right] f_{s s, k}^{+},
$$

$f_{s s}^{-}$being the Fukui function for decreasing spin number. Approximations for these spin Fukui functions can be computed using the approximations proposed by Galvan et $a l^{43 a}$ :

$$
f_{s s}^{+}(\mathbf{r}) \approx \frac{1}{2}\left[\left|\phi_{\mathrm{LUMO}, \alpha}\right|^{2}+\left|\phi_{\mathrm{HOMO}, \beta}\right|^{2}\right],
$$

$$
f_{s S}^{-}(\mathbf{r}) \approx \frac{1}{2}\left[\left|\phi_{\text {номо }, \alpha}\right|^{2}+\left|\phi_{\text {LUMO }, \beta}\right|^{2}\right],
$$

where $\phi_{\mathrm{HOMO}, \alpha}, \phi_{\mathrm{HOMO}, \beta}, \phi_{\mathrm{LUMO}, \alpha}$ and $\phi_{\mathrm{LUMO}, \beta}$ are respectively the $\alpha$ and $\beta$ HOMO and LUMO orbitals.

These concepts were successfully applied in study of the regioselectivity of the $[2+2]$ cyclo-addition of triplet enones on substituted alkenes. ${ }^{45}$ All calculations were performed at the (U)B3LYP level ${ }^{46}$ using the Gaussian 03 program. ${ }^{47}$ The different triplet carbonyl compounds and singlet alkenes studied are given in figure 2. All transition state geometries of the first addition step of the reaction on the triplet energy surface were optimized using the (U)B3LYP level of theory with the 6-31G $(d)$ basis set. The geometries used to compute the DFT based reactivity indices were fully optimized with the $6-311+\mathrm{G}^{* *}$ basis $\operatorname{set}^{48}$ and were confirmed to be minima on the potential energy surface. Molecular properties and reactivity indices were obtained at the $6-311 \mathrm{G}^{* *}$ level; as can be seen, the diffuse function in the basis set used for the optimization of the reacting molecules was dropped when computing the properties because this was found to be more suitable in the case of the Fukui functions and local softnesses, where anionic metastability is frequently observed (for a detailed account, see ref. $[27 \mathrm{~g}])$. Atomic populations were obtained using the natural population analysis (NPA), ${ }^{49}$ in order to compute the condensed Fukui functions and local softnesses. The Fukui functions $f_{s s}$ were computed<smiles>C=C</smiles><smiles>C/C=C\C=O</smiles><smiles>C#C/C=C\C</smiles><smiles>c1ccoc1</smiles><smiles>CC(C)=O</smiles>

Acetone<smiles>CC(=O)c1ccccc1</smiles>

Acetophenone<smiles>C=C(C)C</smiles>

B
Figure 2. Different compounds investigated in this work: $\mathrm{A}=$ ethylene, $\mathrm{B}=$ isobutene, $\mathrm{C}=$ acrylonitrile, $\mathrm{D}=$ acrolein, $\mathrm{E}=$ furan. 
using approximations (24) and (25); the condensed values of densities of $\alpha$ and $\beta$ frontier molecular orbitals on the different atoms were obtained using the Hirshfeld partitioning scheme. ${ }^{50}$ This partitioning scheme has also been found particularly useful to compute condensed values of DFT-based reactivity indices. ${ }^{51}$

\section{Results and discussion}

In the first part of this work, we have investigated the reaction mechanism in some more detail for our series of ketones and substituted ethylenes. The transition state (TS) structures for the first step (figure 3), i.e. the formation of the diradical structures, which are the intermediates of the reaction, were located. In this work, we have only investigated the triplet surface of the attack of the carbonyl oxygen to one of the carbon atoms of the substituted ethylenes. In figure 4, the two different orientations for the carbonyl oxygen attack are depicted: the face-to-face and the face-toedge attack. In the face-to-face attack, an electron on the carbonyl oxygen and an electron on an olefin carbon are spin-coupled to form a $\mathrm{CO}$ bond while the carbonyl and alkene fragments are mutually parallel. When the carbonyl oxygen attacks the olefin in a perpendicular orientation, the face-to-edge attack, the terminal groups on the carbonyl are rotated by approximately 90 degrees. As is generally accepted that the face-to-edge
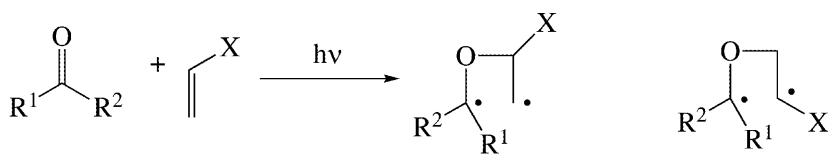

Figure 3. First step $(\mathrm{C}-\mathrm{O}$ attack $)$ of the $[2+2]$ photocyclo-addition of a triplet carbonyl compound to a singlet ethylene.

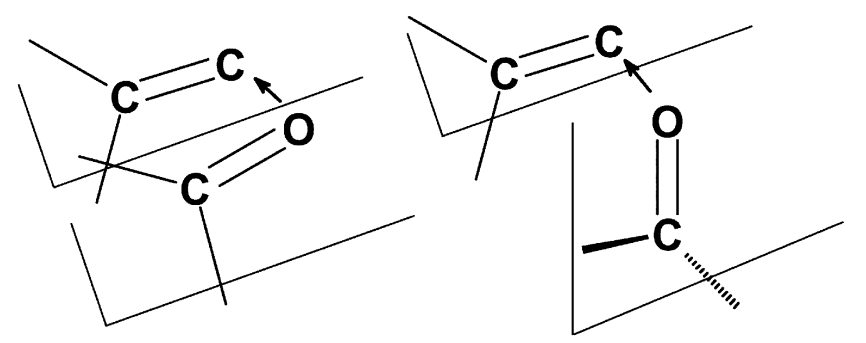

Figure 4. The two different orientations for the carbonyl oxygen attack: the face-to-face (left) and the faceto-edge (right) attack. attack correlates electronically with an $\left(n, \pi^{*}\right)$ excited-state carbonyl compound and a ground state olefin, our attention was mainly focussed on this orientation in the optimization of the different transition states. The different arrangements of the transition states for the $\mathrm{C}-\mathrm{O}$ attack that were considered in this work are presented in figure 5 .

It indeed turns out that the majority of the optimized transition states correspond to a face-to-edge arrangement. In the case of the transition states for the attack of acetone and acetophenone to the substituted carbon atom of the electron poor alkenes, one face-to-edge and one face-to-face (the dihedral angle is $\approx 10^{\circ}$ ) transition states are formed. During the face-to-edge attack on $\mathrm{C}_{1}$ of propenal, in addition to the negative direction of curvature corresponding to forming the $\mathrm{C}-\mathrm{O}$ bond, there is a force constant for the rotation of the ethylenic terminal methylene. Because of this, the transition structure could not be optimized accurately. The attack of the carbonyl oxygen to the $\mathrm{C}_{1}$ of isobutene was found to occur via face-to-face orientation. As can be seen for the activation barriers listed in table 1, for all compounds, the lowest activation barrier is observed for the attack of the carbonyl oxygen on the least substituted carbon atom of the olefin, in agreement with experiment (for the case of furan) and Markovnikov's rule.

Table 1. Activation barriers $(\Delta E$ and $\Delta G)$ for the first step (addition of the carbonyl oxygen to the double bond of the alkenes) in the $[2+2]$ photo-cyclo-addition of acetone and acetophenone to the substituted alkenes considered.

All values were obtained at the B3LYP/6-311+G**// B3LYP/6-31G* level and are given in $\mathrm{kcal} / \mathrm{mol}$.

\begin{tabular}{|c|c|c|c|c|c|}
\hline \multirow[b]{2}{*}{ Alkene } & \multirow[b]{2}{*}{ Structure } & \multicolumn{2}{|c|}{ Acetone } & \multicolumn{2}{|c|}{ Acetophenone } \\
\hline & & $\Delta E$ & $\Delta G$ & $\Delta E$ & $\Delta G$ \\
\hline Ethylene & A & $5 \cdot 4$ & $17 \cdot 2$ & $6 \cdot 1$ & $18 \cdot 7$ \\
\hline \multirow[t]{2}{*}{ Isobutene } & B1 & $5 \cdot 3$ & $16 \cdot 3$ & $6 \cdot 1$ & $19 \cdot 5$ \\
\hline & B2 & $2 \cdot 7$ & $15 \cdot 3$ & $3 \cdot 2$ & $16 \cdot 3$ \\
\hline \multirow[t]{3}{*}{ Acrolein } & $\mathrm{C} 1$ & $4 \cdot 9$ & $16 \cdot 4$ & $8 \cdot 5$ & $21 \cdot 0$ \\
\hline & $\mathrm{C} 2$ & $4 \cdot 0$ & $15 \cdot 9$ & $4 \cdot 4$ & $17 \cdot 4$ \\
\hline & $\mathrm{C} 2^{\prime}$ & $4 \cdot 4$ & $16 \cdot 9$ & $6 \cdot 6$ & $19 \cdot 2$ \\
\hline \multirow[t]{4}{*}{ Acrylonitrile } & D1 & $5 \cdot 9$ & $16 \cdot 8$ & $9 \cdot 3$ & $21 \cdot 9$ \\
\hline & $\mathrm{D} 1^{\prime}$ & $5 \cdot 6$ & $17 \cdot 0$ & $6 \cdot 6$ & $19 \cdot 1$ \\
\hline & D2 & $3 \cdot 5$ & $16 \cdot 0$ & $3 \cdot 5$ & $16 \cdot 3$ \\
\hline & $\mathrm{D} 2^{\prime}$ & $3 \cdot 7$ & $16 \cdot 1$ & $4 \cdot 3$ & $17 \cdot 4$ \\
\hline \multirow[t]{4}{*}{ Furan } & E1 & $8 \cdot 5$ & $21 \cdot 3$ & 7.9 & $21 \cdot 5$ \\
\hline & $\mathrm{E} 1^{\prime}$ & $11 \cdot 1$ & $24 \cdot 0$ & $10 \cdot 6$ & $24 \cdot 0$ \\
\hline & E2 & $2 \cdot 7$ & $15 \cdot 3$ & $3 \cdot 4$ & $16 \cdot 7$ \\
\hline & $\mathrm{E} 2^{\prime}$ & $4 \cdot 4$ & $17 \cdot 0$ & $3 \cdot 0$ & $16 \cdot 4$ \\
\hline
\end{tabular}


K1

K2<smiles>[R11]C=CC([R])([B])OC([R2])C</smiles>

A;B1<smiles></smiles>

B2
$\mathrm{R} 1=\mathrm{H}, \mathrm{Me}$ $\mathrm{R} 2=\mathrm{Me}, \mathrm{Ph}$

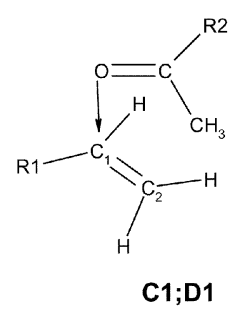

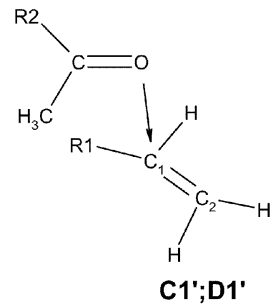<smiles>[R2]C(C)=C(C)C=O</smiles><smiles>[R]C1=CC=CC1[R]([H])=C</smiles>

$\mathrm{R} 1=\mathrm{CHO}, \mathrm{CN}$ $\mathrm{R} 2=\mathrm{Me}, \mathrm{Ph}$

C2';D2'<smiles></smiles>

E1<smiles></smiles>

E1'<smiles></smiles>

E2<smiles>[R]C(C)=C1C=CO[C]([2H])O1</smiles>

E2'

$\mathrm{R} 2=\mathrm{Me}, \mathrm{Ph}$

Figure 5. Structures of the different transition states obtained in this work.

Table 2. Vertical ionization energies $I$, electron affinities $A$, global softnesses $S$, condensed spin density $N_{s}$, Fukui functions $f$ and local softnesses $s$ for triplet acetone and acetophenone obtained at the B3LYP/6-311G**//B3LYP/6$311+\mathrm{G}^{* *}$ level.

\begin{tabular}{lccccccccccc}
\hline Molecule & $I(\mathrm{eV})$ & $A(\mathrm{eV})$ & $S$ (a.u.) & Atom & $N_{s}$ & $f^{-}$(a.u.) & $f^{+}$(a.u.) & $f^{0}$ (a.u.) & $s^{-}($a.u. $)$ & $s^{+}($a.u. $)$ & $s^{0}($ a.u. $)$ \\
\hline Acetone & 7.236 & \multirow{2}{*}{1.758} & \multirow{2}{*}{4.967} & $\mathrm{C}$ & 0.705 & 0.401 & 0.014 & 0.207 & 1.990 & 0.070 & 1.030 \\
& & & & $\mathrm{O}$ & 1.056 & 0.204 & 0.562 & 0.383 & 1.014 & 2.791 & 1.902 \\
Acetophenone & 6.209 & \multirow{2}{*}{2.850} & \multirow{2}{*}{8.101} & $\mathrm{C}$ & 0.474 & 0.252 & -0.068 & 0.092 & 2.043 & -0.549 & 0.747 \\
& & & & $\mathrm{O}$ & 1.041 & 0.103 & 0.541 & 0.322 & 0.835 & 4.379 & 2.607 \\
\hline
\end{tabular}

Next, we assess the regioselectivity of the first addition step of the oxygen of the triplet carbonyl compounds to the alkenes using the well-known "non-spin-polarized" DFT based reactivity indices and the local hard and soft acids and bases principle. ${ }^{37}$ In this approach, one is looking at the softnesss resemblance of the interacting sites, in this case by considering the smallest absolute value of the difference in local softness between the oxygen of either the triplet acetone or acetophenone on the one hand and one of the carbon atoms of the double bond $\left(C_{1}\right.$ or $C_{2}$ ) in the alkenes on the other, i.e. considering:

$$
\begin{aligned}
& \sum_{0}^{1}=\left|s_{0}-s_{C 1}\right|, \\
& \sum_{0}^{2}=\left|s_{0}-s_{C 2}\right|,
\end{aligned}
$$

This approach has been termed "softness-matching". 37

Within this approach we can either use the $s^{+} / s^{-}$softnesses, considering the interaction to be an interaction between an electrophile and a nucleophile, which was adopted in the work of Nguyen et al. ${ }^{11}$ We could also perform the softness matching using 
Table 3. Vertical ionization energies $I$, electron affinities $A$, global softnesses $S$, Fukui functions $f$ and local softnesses $s$ for the singlet alkenes obtained at the B3LYP/6-311G**//B3LYP/6-311+G** level.

\begin{tabular}{|c|c|c|c|c|c|c|c|c|c|c|}
\hline Molecule & $I(\mathrm{eV})$ & $A(\mathrm{eV})$ & $S$ (a.u.) & Atom & $f^{-}$(a.u.) & $f^{+}$(a.u.) & $f^{0}$ (a.u.) & $s^{-}$(a.u.) & $s^{+}$(a.u.) & $s^{0}$ (a.u.) \\
\hline Ethylene & $10 \cdot 556$ & $-2 \cdot 761$ & $2 \cdot 043$ & $\mathrm{C}_{1}=\mathrm{C}_{2}$ & 0.423 & $0 \cdot 386$ & 0.404 & $0 \cdot 863$ & 0.790 & 0.826 \\
\hline Isobutene & $9 \cdot 239$ & $-2 \cdot 639$ & $2 \cdot 291$ & $\begin{array}{l}\mathrm{C}_{1} \\
\mathrm{C}_{2}\end{array}$ & $\begin{array}{l}0 \cdot 268 \\
0 \cdot 379\end{array}$ & $\begin{array}{l}0 \cdot 165 \\
0 \cdot 322\end{array}$ & $\begin{array}{l}0 \cdot 217 \\
0 \cdot 351\end{array}$ & $\begin{array}{l}0 \cdot 615 \\
0 \cdot 868\end{array}$ & $\begin{array}{l}0 \cdot 379 \\
0.739\end{array}$ & $\begin{array}{l}0.497 \\
0.803\end{array}$ \\
\hline Acrylonitrile & $10 \cdot 727$ & $-0 \cdot 638$ & $2 \cdot 394$ & $\begin{array}{l}\mathrm{C}_{1} \\
\mathrm{C}_{2}\end{array}$ & $\begin{array}{l}0 \cdot 205 \\
0 \cdot 321\end{array}$ & $\begin{array}{l}0 \cdot 205 \\
0 \cdot 347\end{array}$ & $\begin{array}{l}0 \cdot 205 \\
0 \cdot 334\end{array}$ & $\begin{array}{l}0.492 \\
0.768\end{array}$ & $\begin{array}{l}0 \cdot 490 \\
0 \cdot 831\end{array}$ & $\begin{array}{l}0.491 \\
0.800\end{array}$ \\
\hline Acrolein & 9.903 & $-0 \cdot 447$ & $2 \cdot 629$ & $\begin{array}{l}\mathrm{C}_{1} \\
\mathrm{C}_{2}\end{array}$ & $\begin{array}{r}-0 \cdot 018 \\
0 \cdot 194\end{array}$ & $\begin{array}{l}0 \cdot 090 \\
0 \cdot 305\end{array}$ & $\begin{array}{l}0 \cdot 036 \\
0 \cdot 249\end{array}$ & $\begin{array}{r}-0.047 \\
0.510\end{array}$ & $\begin{array}{l}0 \cdot 238 \\
0 \cdot 801\end{array}$ & $\begin{array}{l}0.095 \\
0.655\end{array}$ \\
\hline Furan & 8.892 & $-2 \cdot 556$ & $2 \cdot 377$ & $\begin{array}{l}\mathrm{C}_{1} \\
\mathrm{C}_{2}\end{array}$ & $\begin{array}{l}0 \cdot 120 \\
0 \cdot 265\end{array}$ & $\begin{array}{l}0 \cdot 095 \\
0 \cdot 247\end{array}$ & $\begin{array}{l}0 \cdot 107 \\
0 \cdot 256\end{array}$ & $\begin{array}{l}0.285 \\
0.631\end{array}$ & $\begin{array}{l}0 \cdot 225 \\
0 \cdot 587\end{array}$ & $\begin{array}{l}0.255 \\
0.609\end{array}$ \\
\hline
\end{tabular}

Table 4. Transfer energies for one electron from the triplet carbonyl compound to the alkene $\left(I_{\text {carb }}-A_{\text {alkene }}\right)$ and vice versa $\left(I_{\text {alkene }}-A_{\text {carb }}\right)$, obtained at the B3LYP/6$311 \mathrm{G}^{* *} / / 6-311+\mathrm{G}^{* *}$ level. All values are in $\mathrm{eV}$.

\begin{tabular}{|c|c|c|c|}
\hline Enone & Alkene & $I_{\text {carb }}-A_{\text {alkene }}$ & $I_{\text {alkene }}-A_{\text {carb }}$ \\
\hline \multirow[t]{5}{*}{ Acetone } & Ethylene & $10 \cdot 00$ & $8 \cdot 80$ \\
\hline & Isobutene & $9 \cdot 88$ & $7 \cdot 48$ \\
\hline & Acrylonitrile & $7 \cdot 87$ & 8.97 \\
\hline & Acrolein & $7 \cdot 68$ & $8 \cdot 15$ \\
\hline & Furan & $9 \cdot 79$ & $7 \cdot 13$ \\
\hline \multirow[t]{5}{*}{ Acetophenone } & Ethylene & 8.97 & $7 \cdot 71$ \\
\hline & Isobutene & $8 \cdot 85$ & $6 \cdot 39$ \\
\hline & Acrylonitrile & $6 \cdot 85$ & $7 \cdot 88$ \\
\hline & Acrolein & $6 \cdot 66$ & $7 \cdot 05$ \\
\hline & Furan & $8 \cdot 76$ & $6 \cdot 04$ \\
\hline
\end{tabular}

the local softness for a radical attack $s^{0}$ for both reagents, assuming the reaction to be a radical-radical interaction. In tables 2 and 3, the reactivity descriptors for the triplet carbonyl compounds and the singlet alkenes are listed. Using the vertical ionization energy (I) and electron affinity $(A)$ one can approximate the energy needed to move an electron from the carbonyl compound to the alkene ( $I_{\text {carb }}-$ $\left.A_{\text {alkene }}\right)$ and the energy needed to move an electron fron the alkene to the enone $\left(I_{\text {alkene }}-A_{\text {carb }}\right)$. These transfer energies are listed in table 4 . As can be seen, for the interaction of the triplet carbonyl compounds and the electron-rich alkenes, including ethylene, the transfer energy for an electron from the alkene to the excited carbonyl compound is lower that the reverse process, corresponding to an interaction of an electrophilic excited state species with the ground state alkene. In this case, one thus has to consider $s^{+}$on the carbonyl compound and $s^{-}$on the alkenes. For the reaction with the electron-poor alkenes (i.e. acry- lonitrile and acrolein), the transfer energy for an electron from the triplet carbonyl compounds to the alkenes is the lowest. It thus appears that these alkenes are now operating as electrophilic species, and one thus considers $s^{+}$for these compounds in (26) and (27) together with s- for the triplet carbonyl compounds.

The values of $\sum_{0}^{1}$ and $\sum_{0}^{2}$ obtained for the addition of the triplet carbonyl compounds to the alkenes, computed using (26) and (27), considering either an interaction between a nucleophile and an electrophile $\left(s^{+} / s^{-}\right)$or the interaction between two radicals $\left(s^{0} / s^{0}\right)$ are listed in table 5 . As can be seen, the smallest softness difference always occurs for the interaction of the oxygen of the triplet carbonyl compound with carbon atom 2 of the alkenes, in agreement with the computed activation barriers for this first addition step. From table 1, it can indeed be seen that the activation barrier for the addition of the oxygen atom on carbon 2 is always the lowest.

Finally, we investigate the regioselectivity in the different cases studied within the framework of spinpolarized conceptual DFT, as this reaction involves a singlet alkene and a triplet carbonyl compound. In the spin-polarized approach, the first step of this reaction can now be divided into two parts, both at constant external potential $\mathrm{V}$, as schematically shown in figure 6. In the first step, a rearrangement of the spin density occurs in both reacting molecules. This amounts to a decrease of the spin number on the excited $\alpha, \beta$-unsaturared carbonyl compound, resulting in stabilisation, and an increase of the spin number on the alkene, resulting in destabilization of the latter. The magnitude of the change of the spin density of the different sites in the interacting molecules upon a change of their total spin number $N_{s}$ is governed by the generalized Fukui function given in (15); for 
Table 5. The values of $\sum_{0}^{i}$ for the addition of the triplet carbonyl compounds to the alkenes.

Values computed using (24), considering either an interaction between a nucleophile and an electrophile $\left(s^{+} / s^{-}\right)$, or the interaction between two radicals $\left(s^{0} / s^{0}\right)$. All values are in a.u.

\begin{tabular}{|c|c|c|c|c|c|}
\hline \multirow[b]{2}{*}{ Alkene } & & \multicolumn{2}{|c|}{ Acetone } & \multicolumn{2}{|c|}{ Acetophenone } \\
\hline & & $s^{+} / s^{-}$ & $s^{0} / s^{0}$ & $\mathrm{~s}^{+} / \mathrm{s}^{-}$ & $s^{0} / s^{0}$ \\
\hline Ethylene & $\sum_{0}^{1}=\Sigma_{0}^{2}$ & 1.927 & 1.076 & $3 \cdot 516$ & $1 \cdot 781$ \\
\hline \multirow[t]{2}{*}{ Isobutene } & $\sum_{0}^{1}$ & $2 \cdot 176$ & $1 \cdot 405$ & $3 \cdot 764$ & $2 \cdot 110$ \\
\hline & $\sum_{0}^{2}$ & $1 \cdot 923$ & $1 \cdot 099$ & $3 \cdot 511$ & $1 \cdot 804$ \\
\hline \multirow[t]{2}{*}{ Acrylonitrile } & $\sum_{0}^{1}$ & $0 \cdot 525$ & $1 \cdot 412$ & $0 \cdot 345$ & $2 \cdot 116$ \\
\hline & $\sum_{0}^{2}$ & $0 \cdot 183$ & $1 \cdot 103$ & $0 \cdot 004$ & $1 \cdot 807$ \\
\hline \multirow[t]{2}{*}{ Acrolein } & $\sum_{0}^{1}$ & $0 \cdot 777$ & $1 \cdot 807$ & $0 \cdot 597$ & $2 \cdot 512$ \\
\hline & $\sum_{0}^{2}$ & $0 \cdot 214$ & $1 \cdot 247$ & $0 \cdot 034$ & $1 \cdot 952$ \\
\hline \multirow[t]{2}{*}{ Duran } & $\sum_{0}^{1}$ & $2 \cdot 506$ & $1 \cdot 648$ & $4 \cdot 095$ & $2 \cdot 352$ \\
\hline & $\sum_{0}^{2}$ & $2 \cdot 160$ & $1 \cdot 294$ & $3 \cdot 749$ & 1.998 \\
\hline
\end{tabular}

Table 6. Values of the density of the $\alpha$ HOMO, the $\alpha$ LUMO, the $\beta$ HOMO and $\beta$ LUMO orbitals, condensed to the $\mathrm{O}$ and $\mathrm{C}_{2}$ atoms of the triplet carbonyl compounds, using the Hirshfeld partitioning scheme.

In the last column, the condensed generalized Fukui function $f_{\text {ss }}^{-}$, obtained using (24) and $(25)$ is given. All values are in a.u.

\begin{tabular}{lcccccc}
\hline Enone & Atom & $\left|\phi_{\mathrm{HOMO}, \alpha}\right|^{2}$ & $\left|\phi_{\mathrm{LUMO}, \alpha}\right|^{2}$ & $\left|\phi_{\mathrm{HOMO}, \beta}\right|^{2}$ & $\left|\phi_{\mathrm{LUMO}, \beta}\right|^{2}$ & $f_{\mathrm{ss}}^{-}$ \\
\hline Acetone & $\mathrm{C}$ & 0.519 & 0.045 & 0.149 & 0.091 & 0.305 \\
& $\mathrm{O}$ & 0.219 & 0.021 & 0.669 & 0.718 & 0.468 \\
Acetophenone & $\mathrm{C}$ & 0.313 & 0.007 & 0.005 & 0.085 & 0.199 \\
& $\mathrm{O}$ & 0.134 & 0.002 & 0.009 & 0.729 & 0.432 \\
\hline
\end{tabular}

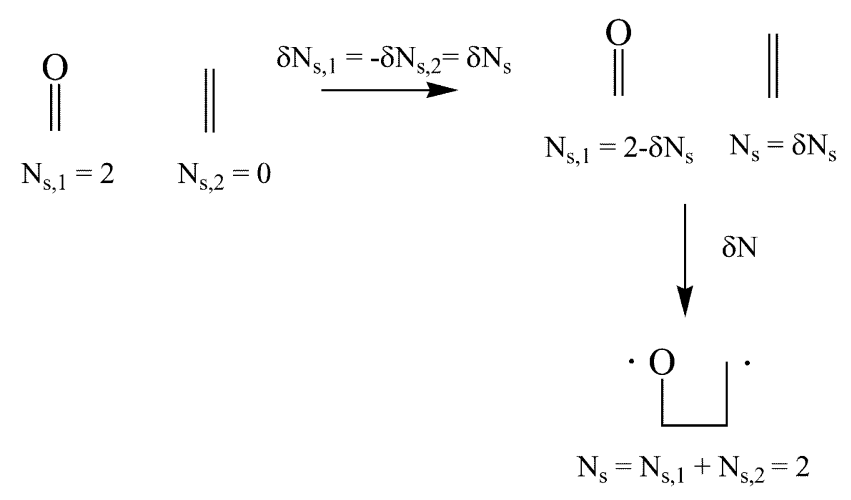

Figure 6. Spin-polarized description of the first step of the Paterno-Büchi reaction (constant external potential). In the first step, a spinpolarization of both reacting molecule occurs (change in $N_{s}$ ), followed by the charge transfer (change in the number of electrons $N$ of both reacting species), forming the 1,4-biradical intermediate of the reaction.
Table 7. Spin potentials of the singlet ground state $\mu^{+}\left(S_{0}\right)$, the triplet excited state $\mu^{-}\left(T_{1}\right)$, the spin hardnesses $\eta_{S S}^{0}$ and the spin philicities $\omega_{s}^{+}$of the singlet alkenes.

All values are in a.u.

\begin{tabular}{lcccc}
\hline Alkene & $\mu^{-}\left(T_{1}\right)$ & $\mu^{+}\left(S_{0}\right)$ & $\eta_{S S}^{0}$ & $\omega_{s}^{+}$ \\
\hline Ethylene & 0.0257 & $0 \cdot 1404$ & -0.0573 & -0.1718 \\
Isobutene & 0.0283 & 0.1327 & -0.0522 & -0.1687 \\
Acrylonitrile & 0.0221 & 0.1162 & -0.0470 & -0.1436 \\
Acrolein & 0.0204 & 0.0952 & -0.0374 & -0.1212 \\
Furan & 0.0346 & 0.1169 & -0.0412 & -0.1660 \\
\hline
\end{tabular}

the triplet carbonyl compound, this Fukui function has to be computed in the direction of decreasing $N_{s}$, whereas for the singlet alkenes, the direction of increasing $N_{s}$ has to be considered. These condensed generalised Fukui functions, computed using the approximations given in (24) and (25), are given in table 
Table 8. Values of the density of the $\alpha$ HOMO (= $\beta$ HOMO) and the $\alpha$ LUMO ( $=\beta$ LUMO) orbitals, condensed to the $C_{1}$ and $C_{2}$ atoms of the singlet alkenes considered in this work, using the Hirshfeld partitioning scheme.

In the last two columns, the condensed generalized Fukui function $f_{S S}^{+}$, obtained using (36) is given, together with the local spin-philicities $\omega_{s}^{+}$. All values are in a.u.

\begin{tabular}{lccccc}
\hline Alkene & Atom & $\left|\phi_{\mathrm{HOMO}, \alpha}\right|^{2}$ & $\left|\phi_{\mathrm{LUMO}, \alpha}\right|^{2}$ & $f_{\mathrm{ss}}^{+}$ & $\omega_{s}^{+}$ \\
\hline Ethylene & $\mathrm{C}_{1}$ & 0.439 & 0.398 & 0.418 & -0.072 \\
& $\mathrm{C}_{2}$ & 0.439 & 0.398 & 0.418 & -0.072 \\
\multirow{2}{*}{ Isobutene } & $\mathrm{C}_{1}$ & 0.312 & 0.315 & 0.314 & -0.053 \\
& $\mathrm{C}_{2}$ & 0.433 & 0.347 & 0.390 & -0.066 \\
\multirow{2}{*}{ Acrylonitrile } & $\mathrm{C}_{1}$ & 0.245 & 0.245 & 0.245 & -0.035 \\
& $\mathrm{C}_{2}$ & 0.316 & $0 \cdot 363$ & 0.340 & -0.049 \\
\multirow{2}{*}{ Acrolein } & $\mathrm{C}_{1}$ & 0.087 & 0.161 & 0.124 & -0.015 \\
& $\mathrm{C}_{2}$ & 0.015 & 0.292 & 0.154 & -0.019 \\
\multirow{2}{*}{ Furan } & $\mathrm{C}_{1}$ & 0.149 & 0.124 & 0.136 & -0.023 \\
& $\mathrm{C}_{2}$ & 0.296 & 0.243 & 0.269 & -0.045 \\
\hline
\end{tabular}

6 for the triplet carbonyl compounds $\left(f_{s s}^{-}\right)$and in table 8 for the singlet alkenes $\left(f_{s s}^{+}\right)$. As can be seen, $f_{s s}^{+}$is always the largest on the carbonyl oxygen atom of the triplet carbonyl compounds, in agreement with the NPA spin density values $N_{s}$ given in table 2 for these compounds. In the case of the alkenes, $f_{s s}^{+}$is always higher on the $\mathrm{C}_{2}$ atom of the double bond. It thus appears that the correct regioselectivity can be predicted by presuming a spin coupling (first step in figure 6) of these two sites that exhibit the largest values of the generalized Fukui function. This finding seems to be remeniscent of some kind of hard and soft acids and bases principle within the context of spin-polarized DFT.

Table 7 lists the spin potentials, spin hardnesses and the global spin-philicities of the singlet alkenes studied in this work. As can be seen, all the spinphilicities are negative, in agreement with the fact that the energy change when going from the singlet state, the ground state, to the first excited triplet state (i.e. a change with $\Delta N_{s}=2$ ) is positive. In previous work, this quantity has been proven to correlate with the singlet-triplet gaps of a series of singlet ground state carbenes, silylenes, germylenes and stannylenes. Recently, this correlation was confirmed by Olah et $a l^{41 \mathrm{~g}}$ for a series of nitrenes and phosphinidenes. Table 8 lists the local spin-philicities of the different alkenes studied in this work. As can be seen, the most negative spin-philicities occur on $\mathrm{C}_{2}$, in agreement with the fact that the condensed value of is $f_{s s}^{-}$always the largest on this atom. The local contribution of this atom in the energy rise due to the increase of the spin number can thus considered to be larger than the contribution of $\mathrm{C} 1$. In this case however, this does not seem to be the decisive factor in prediction of the regioselectivity.

\section{Conclusions}

In this contribution, we have presented a study of the regioselectivity of the photochemical [2+2] cycloaddition of carbonyl compounds with ground state alkenes, the Paterno-Büchi reaction, using DFTbased reactivity descriptors.

In a first part, we have located the different transition states for the first radical coupling step on the triplet surface for the reaction of triplet acetone and acetophenone with a series of electron-rich and electron-poor alkenes, focussing our attention exclusively on the O-attack. Next, we have investigated the regioselectivity using the local softness within the framework of the local hard and soft acids and bases principle. Within this approach, the interaction was investigated as either the interaction between a nucleophile and an electrophile or the interaction of two radicalar species on the other hand. Both approaches systematically yield a regioselectivity that is completely in agreement with the computed activation barriers.

Finally, the regioselectivity of this reaction was investigated using chemical concepts introduced within the framework of spin-polarized conceptual DFT. In this case, the local spin-philicity does not appear the 
determining factor for the observed regioselectivity. The correct regioselectivity emerges from considering an interaction between the sites that undergo the largest change in spin number when the total spin number of the molecule is changing.

\section{Acknowledgements}

FDP and PG wish to thank the VUB and the Fund for Scientific Research Flanders-Belgium (FWO) for continuous support. BP and TV thank an OTKA grant for financial support.

\section{References}

1. Paterno E and Chieffi G 1909 Gazz. Chim. Ital. 39341

2. Büchi G, Inman C G and Lipinsky E S 1954 J. Am. Chem. Soc. 764327

3. Turro N J 1978 Modern molecular photochemistry (Menlo Park, CA: Benjamin/Cummings)

4. March J and Smith M B 2001 March's advanced organic chemistry (New York: Wiley)

5. Turro N J, Wriede P A, Dalton J C, Arnold D and Glick A 1968 J. Am. Chem. Soc. 906863

6. Turro N J and Wriede P A 1968 J. Am. Chem. Soc. 90 6863

7. Barltrop J A and Carless H A J 1972 J. Am. Chem. Soc. 948761

8. Dowd P, Gold A and Sachdev K 1970 J. Am. Chem. Soc. 925725

9. Palmer I J, Ragazos I N, Bernardi F, Olivucci M and Robb M A 1994 J. Am. Chem. Soc. 1162121

10. Kutateladze A G 2001 J. Am. Chem. Soc. 1239279

11. Sengupta D, Chandra A K and Nguyen M T 1997 J. Org. Chem. 626404

12. Yang N C and Eisenhardt W 1971 J. Am. Chem. Soc. 931279

13. Muller F and Mattay J 1993 Chem. Rev. 9399

14. Dowd P, Gold A and Sachdev K 1970 J. Am. Chem. Soc. 925725

15. Arnold D R, Hinman R L and Glick A H 1964 Tetrahedron Lett. 1425

16. Arnold D R 1968 Adv. Photochem. 6301

17. Farid S, Hartman S E and DeBoer C D $1975 \mathrm{~J}$. Am. Chem. Soc. 97808

18. Freilich S C and Peters K S 1985 J. Am. Chem. Soc. 1073819

19. Zimmerman H 1966 Science $\mathbf{1 5 3} 837$

20. D'Auria M, Emanuele L and Racioppi R $2004 J$. Photochem. Photobiol. A163 103

21. Ciufolini M C, Rivera-Fortin M A, Zuzukin V and Whitmire K H 1994 J. Am. Chem. Soc. 981994

22. Hu S and Neckers D C 1997 J. Org. Chem. 62564

23. Howell A R, Fan R and Truong A 1996 Tetrahedron Lett. 378651

24. Fleming S A and Gao J J 1997 Tetrahedron Lett. 38 5407
25. Griesbeck A G and Bondock S 2001 J. Am. Chem. Soc. 1236191

26. Adam W, Peters K, Peters E M and Stegmann V R 2000 J. Am. Chem. Soc. 1222958

27. (a) Parr R G and Yang W 1989 Density functional theory of atoms and molecules (New York: Oxford University Press); (b) Parr R G and Yang W 1995 Annu. Rev. Phys. Chem. 46 701; (c) Kohn W, Becke A D and Parr R G 1996 J. Phys. Chem. 100 12974; (d) Chermette H 1999 J. Comput. Chem. 20 129; (e) Geerlings P, De Proft F and Langenaeker W 1999 Adv. Quant. Chem. 33 303; (f) Geerlings $\mathrm{P}$ and De Proft F 2002 Int. J. Mol. Sci. 3 276; (g) Geerlings P, De Proft F and Langenaeker W 2003 Chem. Rev. 103 1793

28. Parr R G, Donnelly R A, Levy M and Palke W E 1978 J. Chem. Phys. 683801

29. For a detailed account on the different electronegativity scales introduced see e.g. Mullay J 1987 in Electronegativity: Structure and bonding (eds) K D Sen and C K Jørgenson (Berlin, Heidelberg: SpringerVerlag) vol 66, p. 1

30. (a) Pearson R G 1963 J. Am. Chem. Soc. 85 3533; (b) Pearson R G 1997 Chemical hardness (New York: John Wiley \& Sons)

31. Parr R G and Pearson R G 1983 J. Am. Chem. Soc. 1057512

32. Yang W and Parr R G 1985 Proc. Natl. Acad. Sci. USA 826723

33. Lee C, Yang W and Parr R G 1988 J. Mol. Struct. (Theochem.) 163305

34. Parr R G and Yang W 1984 J. Am. Chem. Soc. 106 4049

35. Yang W and Mortier W J 1986 J. Am. Chem. Soc. 1065708

36. Chattaraj P K, Lee H and Parr R G 1991 J. Am. Chem. Soc. 1131855

37. (a) Gázquez J L 1993 in Chemical hardness: Structure and bonding (ed.) K D Sen vol. 80, p. 27; (b) Méndez F and Gázquez J L 1994 J. Am. Chem. Soc. 116 9298; (c) Gázquez J L and Méndez F $1994 J$. Phys. Chem. 98 4591; (d) Méndez F and Gázquez J L 1994 Proc. Indian Acad. Sci. 106 183; (e) Damoun S, Van de Woude G, Méndez F and Geerlings P 1997 J. Phys. Chem. A101 886; (f) Geerlings P and De Proft F 2000 Int. J. Quantum Chem. 80227

38. Hohenberg P and Kohn W 1964 Phys. Rev. 136 B864

39. Runge E and Gross E K U 1984 Phys. Rev. Lett. 52997

40. Kohl H and Dreizler R M 1986 Phys. Rev. Lett. 56737

41. (a) Chattaraj P K and Poddar J 1998 J. Phys. Chem. A102 9944; (b) Chattaraj P K and Poddar J 1999 J. Phys. Chem. A103 1274; (c) Chattaraj P K and Poddar J 1999 J. Phys. Chem. A103 8691; (d) Sengupta D, Chandra A K and Nguyen M T 1997 J. Org. Chem. 62 6404; (e) Mendez F and Garcia-Gariday M A J. Org. Chem. 64 7061; (f) Oláh J, De Proft F, Veszprémi T and Geerlings P 2004 J. Phys. Chem. A108 490; (g) Oláh J, Veszprémi T and Nguyen M T 2005 Chem. Phys. Lett. 401337

42. (a) Von Bart U and Hedin L 1972 J. Phys. C5 1629; (b) Rajagopal A K and Callaway J 1973 Phys. Rev. 
B7 1912; (c) Gunnarson O and Lundqvist B I 1976 Phys. Rev. B13 4274

43. (a) Galván M, Vela A and Gázquez J L 1988 J. Phys. Chem. 92 6470; (b) Galván M and Vargas R 1992 J. Phys. Chem. 96 1625; (c) Vargas R and Galván M 1996 J. Phys. Chem. 100 14651; (d) Vargas R, Galván M and Vela A 1998 J. Phys. Chem. A102 3134; (e) Vargas R, Cedillo A, Garza J and Galván M 2002 In Reviews of modern quantum chemistry: A celebration to the contributions of $R G$ Parr (ed.) K D Sen (Singapore, World Scientific) p. 936

44. Pérez P, Andrés J, Safont V S, Tapia O and Contreras R 2002 J. Phys. Chem. A106 5353

45. De Proft F, Fias S, Van Alsenoy C and Geerlings P 2005 J. Phys. Chem. A108 6335

46. (a) Becke A D 1993 J. Chem. Phys. 98 5648; (b) Lee C, Yang W and Parr R G 1988 Phys. Rev. B37 785; (c) Stevens P J, Delvin F J, Chablaoski C F and Frisch M J 1994 J. Phys. Chem. 9811623

47. Frisch M J et al 2004 Gaussian 03 Revision B03, Gaussian Inc., Wallingford, CT

48. For a detailed account on these types of basis sets see e.g. W J Hehre, L Radom, P v R Schleyer and J A Pople 1986 Ab initio molecular orbital theory (New York: Wiley)

49. (a) Reed A E, Weinstock R B and Weinhold F 1985 J. Chem. Phys. 83 735; (b) Reed A E and Weinhold F 1985 J. Chem. Phys. 83 1736; (c) Reed A E, Curtiss L A and Weinhold F 1988 Chem. Rev. 88899

50. Hirshfeld F L 1977 Theor. Chim. Acta 44129

51. (a) De Proft F, Van Alsenoy C, Peeters A, Langenaeker W and Geerlings P 2002 J. Comput. Chem. 23 1198; (b) De Proft F, Vivas-Reyes R, Peeters A, Van Alsenoy $\mathrm{C}$ and Geerlings P 2003 J. Comput. Chem. 24463 